\title{
TDP-43 accumulation is common in myopathies with rimmed vacuoles
}

\author{
Benno Küsters • Bas J. A. van Hoeve • \\ Helenius Jurgen Schelhaas · Henk ter Laak • \\ Baziel G. M. van Engelen · Martin Lammens
}

Received: 7 November 2008 / Revised: 28 November 2008 / Accepted: 28 November 2008 / Published online: 9 December 2008 (C) The Author(s) 2008. This article is published with open access at Springerlink.com

TAR-DNA-binding protein-43 (TDP-43) is a nuclear protein that is thought to play a regulatory role in gene expression. Ubiquitinated TDP-43 is found in cytoplasmic inclusions in motor neuron disease (MND), frontotemporal lobar degeneration (FTLD-TDP), and MND with FTLD [4]. This shared histopathological hallmark led to the classification of a new class of diseases, the TDP-43-proteinopathies [3]. Recently, TDP-43-positive inclusions have been described in skeletal muscle in sporadic inclusion body myositis (sIBM) and in IBM due to mutations in the valosin-containing protein (VCP) [6]. These myopathies are accompanied by vacuolar changes commonly known as rimmed vacuoles (although these vacuoles are morphologically not always rimmed). These characteristic morphological changes are not exclusive to SIBM and IBM with VCP-mutations but are also found in oculopharyngeal muscular dystrophy (OPMD) [2] and distal myopathies with rimmed vacuoles (DMRV), both of which are hereditary myopathies with inclusion bodies. Although DMRV are a genetically heterogeneous group of diseases, the term is often used in the context of the Nonaka myopathy with

B. Küsters and B. J. A. van Hoeve have contributed equally to this work.

B. Küsters $(\bowtie) \cdot$ H. ter Laak $\cdot$ M. Lammens Department of Pathology,

Radboud University Nijmegen Medical Center, PO 9101, 6500 HB Nijmegen, The Netherlands e-mail: b.kuesters@ pathol.umcn.nl

B. J. A. van Hoeve · H. J. Schelhaas · B. G. M. van Engelen Department of Neurology,

Radboud University Nijmegen Medical Center,

Nijmegen, The Netherlands mutations of the UDP- $N$-acetylglucosamine 2-epimerase/ $N$-acetylmannosamine kinase (GNE) gene [5].

We studied whether TDP-43 aggregates were present in muscle biopsies of sIBM, OPMD and DMRV or in myopathies without the mentioned vacuolar changes.

TDP-43 immunostaining was present in some, but not all, rimmed vacuoles and/or basophilic fibers in most biopsies from patients with sIBM (77.8\%) and OPMD (83.3\%) and in all biopsies from patients with DMRV (one with confirmed GNE mutation) (Table 1). TDP-43 immunostaining was not detected in muscle biopsies from patients with myopathies without vacuolar changes. The pattern of TDP-43 staining was variable: in some biopsies only a single TDP-43 positive inclusion was visible even though more than one rimmed vacuole was present, and in other biopsies multiple TDP-43-positive aggregates were visualized. Both granular and more dot-like aggregates in rimmed vacuoles and basophilic fibers were detected. The morphology of the aggregates was similar in sIBM, OPMD, and DMRV (Fig. 1a-c). Many aggregates also stained positive for ubiquitin (Fig. 1d-f). Occasionally subsarcolemmal TDP-43 staining was present in fibers that did not exhibit rimmed vacuoles or subsarcolemmal basophilia (Fig. 1g).

In conclusion, we confirm the recent data of Weihl et al. [6], showing the presence of TDP-43-positive inclusions in the majority of muscle biopsies from patients with sIBM. However, we found TDP-43-positive aggregates not only in sIBM but also in other vacuolar myopathies. Thus TDP-43positive aggregates would seem to be a general phenomenon among the myopathies associated with rimmed vacuoles. This suggests that abnormal TDP-43 accumulation is more likely to be a common endpoint of (muscle) cell degeneration rather than a primary pathological mechanism underlying these myopathies. These findings may provide insight into the pathobiological relevance of TDP-43 
Table 1 Summarizing results of TDP-43

immunohistochemistry in muscle biopsies
Disease

Numbers of cases (percentage) with TDP-43 positive aggregates

Myopathies with rimmed vacuoles

Sporadic inclusion body myositis

$14 / 18(77.8 \%)$

Oculopharyngeal muscular dystrophy

$5 / 6(83.3 \%)$

Distal myopathy with rimmed vacuoles

$3 / 3(100 \%)$

Myopathies without rimmed vacuoles

Dermatomyositis

$0 / 3(0 \%)$

Polymyositis

$0 / 5(0 \%)$

Metabolic-mitochondrial myopathy

$0 / 5(0 \%)$

Neurogenic atrophy

$0 / 4(0 \%)$

Facio-scapulo-humeral dystrophy $\quad 0 / 2(0 \%)$

Duchennes's muscular dystrophy $\quad 0 / 3(0 \%)$

Becker's muscular dystrophy $\quad 0 / 1(0 \%)$

Congenital central core disease $\quad 0 / 3(0 \%)$

$\begin{array}{ll}\text { Normal biopsy } & 0 / 5(0 \%)\end{array}$

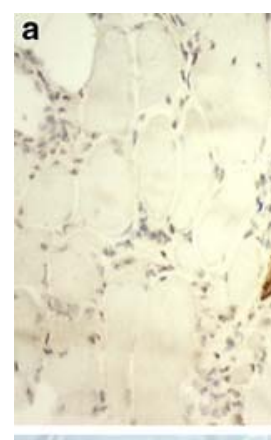

b.
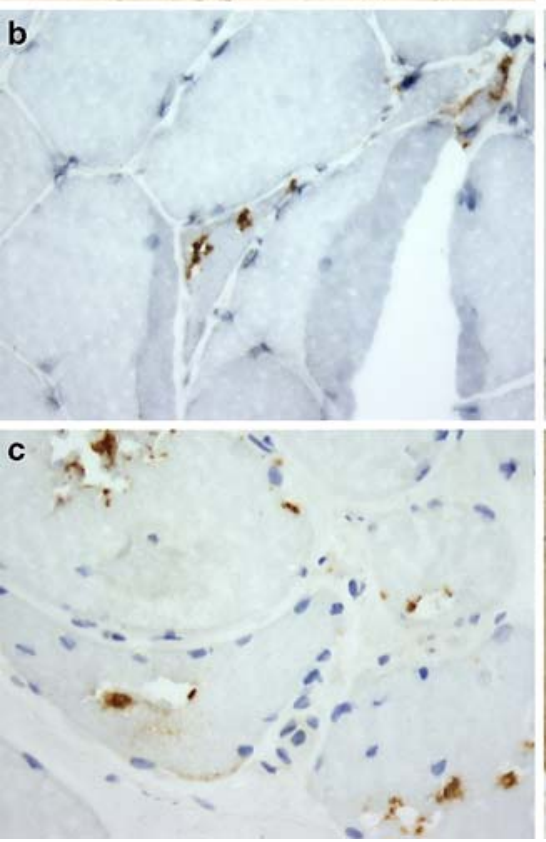

o

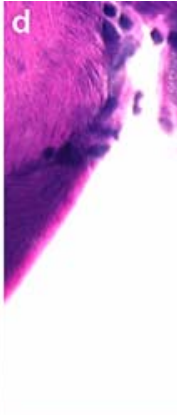

e
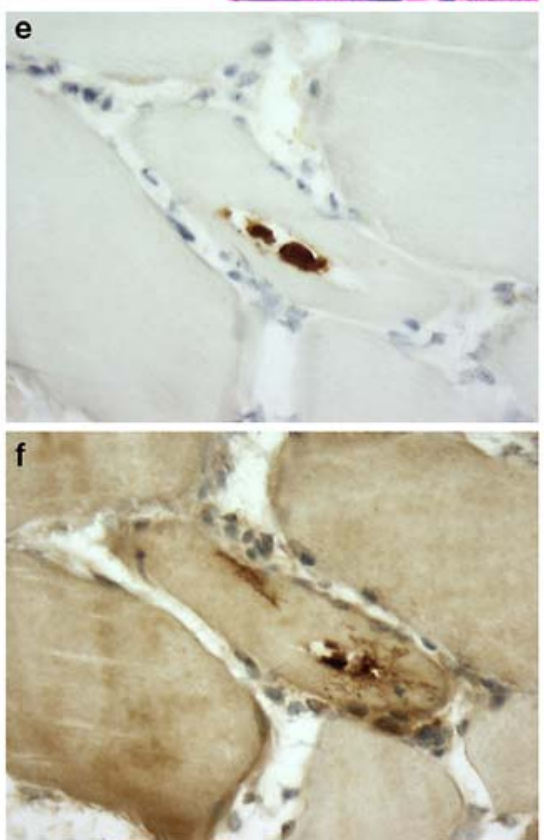

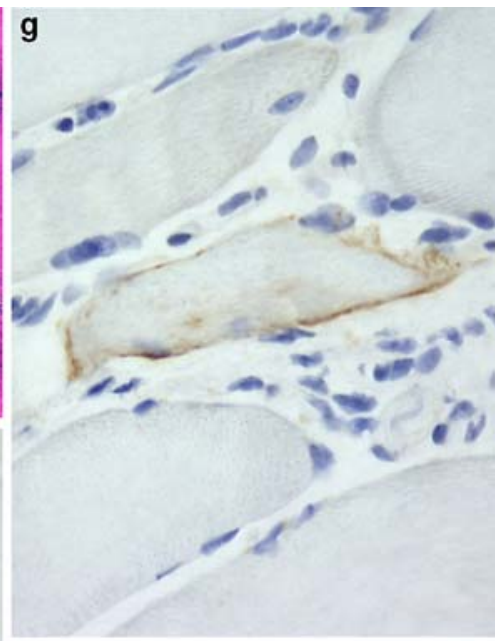

Fig. 1 Myopathies with rimmed vacuoles in frozen muscle sections. a TDP-43 immunohistochemistry (Protein Tech pAB 10782-2-AP) in sporadic inclusion body myositis (sIBM). b TDP-43 staining in distal myopathy with rimmed vacuoles (DMRV). c TDP-43 staining in oculopharyngeal muscular dystrophy (OPMD). d-f Serial section staining of a muscle biopsy from a patient with sIBM. d Hematoxylin-phloxin staining. In the central fiber a rimmed vacuole is present. $\mathbf{e}$ The rimmed vacuole shows granular and dot-like TDP-43 staining. $\mathbf{f}$ The rimmed vacuole also exhibits ubiquitin (DAKO pAB Z0458) positivity. g TDP43 staining in a muscle fiber from a patient with sIBM showing subsarcolemmal staining (Fig. $\mathbf{a} \times 100$ and $\mathbf{b}-\mathbf{g} \times 200$ original magnification) 
aggregates in general and extends the list of proteins that are found in inclusion body myopathies [1].

Open Access This article is distributed under the terms of the Creative Commons Attribution Noncommercial License which permits any noncommercial use, distribution, and reproduction in any medium, provided the original author(s) and source are credited.

\section{References}

1. Askanas V, Engel WK (2008) Inclusion-body myositis: musclefiber molecular pathology and possible pathogenic significance of its similarity to Alzheimer's and Parkinson's disease brains. Acta Neuropathol 116:583-595

2. Brais B, Bouchard JP, Xie YG, Rochefort DL, Chretien N, Tome FM, Lafreniere RG, Rommens JM, Uyama E, Nohira O, Blumen S, Korczyn AD, Heutink P, Mathieu J, Duranceau A, Codere F, Fardeau M, Rouleau GA (1998) Short GCG expansions in the PABP2 gene cause oculopharyngeal muscular dystrophy. Nat Genet 18:164-167
3. Cairns NJ, Bigio EH, Mackenzie IR, Neumann M, Lee VM, Hatanpaa KJ, White CLIII, Schneider JA, Grinberg LT, Halliday G, Duyckaerts C, Lowe JS, Holm IE, Tolnay M, Okamoto K, Yokoo H, Murayama S, Woulfe J, Munoz DG, Dickson DW, Ince PG, Trojanowski JQ, Mann DM (2007) Neuropathologic diagnostic and nosologic criteria for frontotemporal lobar degeneration: consensus of the consortium for frontotemporal lobar degeneration. Acta Neuropathol 114:5-22

4. Neumann M, Sampathu DM, Kwong LK, Truax AC, Micsenyi MC, Chou TT, Bruce J, Schuck T, Grossman M, Clark CM, McCluskey LF, Miller BL, Masliah E, Mackenzie IR, Feldman H, Feiden W, Kretzschmar HA, Trojanowski JQ, Lee VM (2006) Ubiquitinated TDP-43 in frontotemporal lobar degeneration and amyotrophic lateral sclerosis. Science 314:130-133

5. Nishino I, Malicdan MC, Murayama K, Nonaka I, Hayashi YK, Noguchi S (2005) Molecular pathomechanism of distal myopathy with rimmed vacuoles. Acta Myol 24:80-83

6. Weihl CC, Temiz P, Miller SE, Watts G, Smith C, Forman M, Hanson PI, Kimonis V, Pestronk A (2008) TDP-43 accumulation in inclusion body myopathy muscle suggests a common pathogenic mechanism with frontotemporal dementia. J Neurol Neurosurg Psychiatry 79:1186-1189 